\title{
Contribution of meteor flux in the occurrence of sporadic-E (Es) layers over the Arabian Peninsula
}

\author{
Muhammad Mubasshir Shaikh ${ }^{1}$, Govardan Gopakumar ${ }^{1,3}$, Aisha Abdulla Al-owais ${ }^{2}$, Maryam Essa Sharif ${ }^{2}$, and \\ Ilias Fernini ${ }^{1,2,3}$ \\ ${ }^{1}$ Space Weather and Ionosphere Laboratory, Sharjah Academy for Astronomy, Space Sciences and Technology, \\ University of Sharjah, Sharjah, UAE \\ ${ }^{2}$ UAE Meteor Monitoring Network, Sharjah Academy for Astronomy, Space Sciences and Technology, \\ University of Sharjah, Sharjah, UAE \\ ${ }^{3}$ Department of Applied Physics \& Astronomy, University of Sharjah, Sharjah, UAE
}

Correspondence: Muhammad Mubasshir Shaikh (mshaikh@sharjah.ac.ae)

Received: 8 November 2020 - Discussion started: 24 November 2020

Revised: 30 March 2021 - Accepted: 11 April 2021 - Published: 28 May 2021

\begin{abstract}
A sporadic-E (Es) layer is generally associated with a thin-layered structure present in the lower ionosphere, mostly consisting of metallic ions. This metallic ion layer is formed when meteors burn in the upper atmosphere, resulting in the deposition of free metal atoms and ions. Many studies have attributed the presence of the Es layer to the metallic ion layer, specifically when the layer is observed during the nighttime. Using data from a network of meteor monitoring towers and a collocated digital ionosonde radar near the Arabian Peninsula, in this paper, we report our observations of Es layer occurrences together with the meteor count. The trend of monthly averages of Es layer intensity shows a maximum in late spring and early summer months and a minimum in winter months, whereas the meteor counts were highest in winter months and lowest in spring and early summer months. This shows that the presence of the Es layer and the meteor counts have no correlation in time, both diurnally and seasonally. This leads us to conclude that the presence of meteors is not the main cause of the presence of the Es layer over the Arabian Peninsula.
\end{abstract}

\section{Introduction}

Meteors are the visible appearance of extraterrestrial dust, generally known as meteoroids. They appear in the sky when meteoroids ablate in the Earth's atmosphere. Meteors can be categorized as being either part of a shower or of the back- ground meteor flux. There is a vast amount and variety of meteoroid material entering the atmosphere every day (Ceplecha et al., 1998), and its deposition is highly variable spatially as well as temporally. These variations are attributed to the inconsistency of the meteoroid material density surrounding the Earth, seasonal changes of the atmosphere and the Earth's movement around the Sun, the methods of observing them such as the geographical location of the observing site, and geometrical factors related to the observing instruments' capability and positions of sources. This extraterrestrial influx changes the metallic composition of the Earth's atmosphere and lower ionosphere. This happens when meteors burn in the dense atmosphere, resulting in the heating and deposition of free metal atoms and ions (Ceplecha et al., 1998). It is now a well-established fact that the permanent ionized metal layer in the lower ionosphere, at around $90-130 \mathrm{~km}$ altitude, is due to the ablation of meteors in that region (Plane et al., 2015). Meteor observations can be performed with the radio (Stober and Chau, 2015; Lima et al., 2015; Yi et al., 2016) as well as with visual means (Vitek and Nasyrova, 2018; Kozlowski et al., 2019; Fernini et al., 2020). Detection using visual cameras can only be performed during the night compared to radio-based observations that can be performed throughout the day and suitable for estimating total meteor activity. A combination of multiple types of observations may also be used (Brown et al., 2017).

Kopp (1997) showed that the thin-layered structured sporadic-E (Es) layer in the Earth's ionosphere, lying in the 
altitude range of $90-130 \mathrm{~km}$, mostly consists of ionized metal atoms $\mathrm{FeC}, \mathrm{MgC}$, and $\mathrm{NaC}$. At mid-latitudes, the so-called "wind-shear" theory is thought to be the mechanism responsible for this formation (Whitehead, 1989). Therefore, the intensity and occurrence of the Es layer are expected to be proportional to the amount of metal ion content in the lower ionosphere and its chemical processes as well as meteorological processes in the lower ionosphere (Feng et al., 2013; Yu et al., 2015). The nature of the Es layer observed globally has been a function of many factors, such as geographical latitude or observing instruments' sensitivity of the viewing system. For example, the Es layer can be observed at almost all times at some geographical locations around the globe (Shaikh et al., 2020a, b), thus making the term "sporadic" misleading. The behavior of the Es layer over the Arabian Peninsula has not been studied by many. Recently, Shaikh et al. (2020a, b) demonstrated the relationship between L-band scintillation and the occurrence of the Es layer over the Arabian Peninsula. The study also revealed a consistent presence of the Es layer during the nighttime hours, between sunset and sunrise.

In this paper, we report the observations of the Es layer and the meteor counts simultaneously observed during nighttime over the Arabian Peninsula region for the first time. A well-established presence of the Es layer can be observed during all daytime and nighttime hours, with higher intensity around midday hours and lesser intensity at early morning and nighttime hours. A consistent meteor count is also present throughout the 1-year observation period (May 2019-April 2020) reported in this work. It has been observed that the presence of meteors is not the main cause of the presence of nighttime Es over the Arabian Peninsula since the Es layer intensity (average critical frequencies of the Es layers foEs) shows no seasonal correlation with the number of meteors observed. The dependence of Es layer intensity (foEs) due to meteor count has been calculated using linear correlation coefficients. Negative values of correlation coefficient show an anti-correlation relationship between the two data sets.

\section{Data and methodology}

The meteor counts for this study have been obtained in collaboration with the UAE (United Arab Emirates) Meteor Monitoring Network (UAEMMN) project (Fernini et al., 2020). The project aims to monitor and detect meteor occurrences in the region above the United Arab Emirates from sunset to sunrise. To achieve this, three monitoring towers have been constructed and installed in different parts of the country. For each tower, 16 cameras are distributed along with a ring-like structure with lenses of 6 and $8 \mathrm{~mm}$, while the 17th camera utilizes a wide-angle lens and is located at the center of the structure (Fernini et al., 2020). Following a simulation using Systems Tool Kit software (STK: https://www.agi.com/products/50stk, last access: 16 September 2020) as shown in Fig. 1a, the towers' locations were selected as illustrated in Fig. 1b (made using (OGoogle Maps). In Fig. 1, the green color represents the area of the sky covered by the $8 \mathrm{~mm}$ lenses, while red represents the coverage of the $6 \mathrm{~mm}$ lenses. The yellow squares show what the wideangle lens can see and cover. Thus, the STK simulation illustrates how much each tower covers the UAE sky, which adds up to $70 \%$ coverage of the sky. Each of the three UAEMMN towers employs the use of the UFOCapture software developed by SonotaCo (SonotaCo, 2005) to detect meteor occurrences. The software can detect movements from the feed of the cameras on the towers. If a movement or action is detected, it writes the video of the action to the hard disk of the computer, from a few seconds before the action is recognized to a few seconds after the action is completed. During the night, the bright streaks produced by a meteor burning up in the atmosphere allow the software to detect movements from the sudden changes easily in pixel values.

Two other software packages, UFOAnalyzer and UFOOrbit, also developed by SonotaCo (SonotaCo, 2007a, b), are used to calculate parameters that define the meteorite. UFOAnalyzer can calculate the direction and elevation of the meteorite occurrence. If the meteorite is detected by two or more sites, UFOOrbit can calculate the orbit and the radiant point of the meteorite. Figure 2 shows a radiant map obtained as a result of analyses by the software. The radiant map shows radiant points on a sinusoidal projection map of the observed meteors, which is defined as the point in the sky from which the path of the observed meteor begins. For a radiant point to be plotted on the map by the software, double detection of the meteor should occur, meaning that two cameras from at least two different towers need to observe the same meteor. Figure 2 shows the radiant points of meteors observed by the Sharjah and Al-Yahar towers during the period between May 2019 and April 2020. On the map, constellations such as Orionids and Taurids are denoted as J5_Orio, J5_nTa, and sTa, respectively. Hence, the radiant points that are close to a constellation imply that they belong to the respective meteor group. In this figure, there are meteors that belong to the Orionids meteor shower as well as Southern and Northern Taurids and several others, in addition to sporadic meteors that do not belong to any shower. By locating the radiant points on the map, the network ensures its accuracy in terms of linking a meteor to its respective shower. The radiant velocity is color coded as shown in the figure.

The critical frequency of the Es layer (foEs) of the ionosphere is obtained from the ionosonde collocated with the Sharjah meteor monitoring tower. The ionosonde records one ionogram every $15 \mathrm{~min}$, and it has been in operation since May 2019. All ionogram-derived parameters used in this study have been manually scaled. All the data used in this study are available from SWI Lab (2020). Since the data from the meteor towers are only available from nighttime observations and the data from the ionosonde are observed 


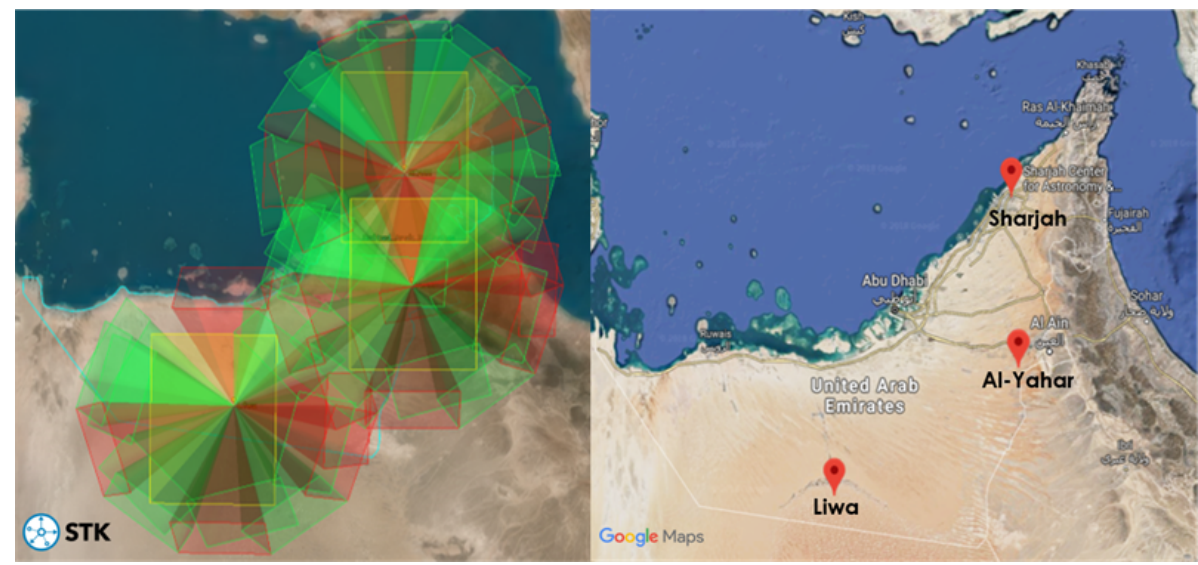

Figure 1. (a) Sky coverage simulation by all cameras using Systems Tool Kit (STK). (b) Location of the towers pinpointed on the UAE map using (C) Google Maps.

Table 1. Location of the instruments used to generate data for this study.

\begin{tabular}{llll}
\hline Instruments & Geographical lat & Geographical long & Specification \\
\hline Sharjah Digital Ionosonde & $25.285381^{\circ} \mathrm{N}$ & $55.464417^{\circ} \mathrm{E}$ & Freq. range $=1-30 \mathrm{MHz}$ \\
Sharjah Meteor Monitoring Tower & $25.235611^{\circ} \mathrm{N}$ & $55.539645^{\circ} \mathrm{E}$ & CCD cameras \\
Al-Yahar Meteor Monitoring Tower & $24.285922^{\circ} \mathrm{N}$ & $55.463625^{\circ} \mathrm{E}$ & $\mathrm{CCD}$ cameras \\
Liwa Meteor Monitoring Tower & $23.104722^{\circ} \mathrm{N}$ & $53.754828^{\circ} \mathrm{E}$ & CCD cameras \\
\hline
\end{tabular}

throughout the day and night, the daily Es intensity (average foEs value) has been used to compare with the daily meteor count to study the impact of the number of meteors present and their influence on the presence of Es (Haldoupis et al., 2007).

\section{Discussion}

Figure 3 shows the observation of the Es layer and meteor count. Figure $3 \mathrm{a}$ and $\mathrm{b}$ show that a constant presence of Es can be observed throughout the year and all hours of the day, with higher intensity (average foEs) around midday hours and lesser intensity at early morning and nighttime hours. An important point to note here is that this observation was performed during a time when the solar activity was low. The average F10.7 solar radio flux value during a 1-year observational period was recorded as $69.43 \mathrm{sfu}$. Only geomagnetically quiet days with an average daily $\mathrm{Kp}$ value of less than 3 were selected for the analysis. It is expected that the Es layer observations would be more substantial as solar cycle 25 gets stronger in the coming years. Figure $3 \mathrm{c}$ shows the hourly meteor count for the whole 1-year observational period. No observations were recorded during the daytime.

Figure 4 shows a comparison between the daily and monthly meteor counts with daily and monthly averages of foEs. Figure $4 \mathrm{a}$ shows all daily observations $(24 \mathrm{~h})$, and Fig. $4 \mathrm{~b}$ provides observations for nighttime only. The trend of monthly averages of the Es layer intensity shows a maximum in late spring and early summer months and minimum in winter months (except for a slight peak in January). At the other end, the monthly meteor count shows an opposite trend with a larger number of meteors observed during NovemberDecember 2019 and very low numbers in the spring and summer months. Both Fig. 4a and b show a very similar trend for foEs averages. The difference is in the intensity of the Es layer, which is greater when all observations are considered due to the inclusion of the daytime Es layer observations. The meteor count is the same in both cases since we have only observed meteors through visual cameras during the nighttime.

The observations presented in Fig. 4 are inconsistent with Younger et al. (2009), who reported meteor flux data observed by radars installed at Esrange $\left(68^{\circ} \mathrm{N}\right)$, Ascension Island $\left(8^{\circ} \mathrm{S}\right)$, and Rothera $\left(68^{\circ} \mathrm{S}\right)$. They showed that, for high latitudes, there is a clear annual cycle present where the maximum count rate is observed in summer, whereas for lowlatitude Ascension Island, the maximum count rates were observed for both solstices (summer and winter). Similar observations were also reported by Singer et al. (2004) using a meteor radar situated at the ALOMAR observatory $\left(69^{\circ} \mathrm{N}\right)$ and Haldoupis et al. (2007) from European latitudes.

There have been other studies that correlate meteor activity with the Es layer seen in ionograms, examples of which include Chandra et al. (2001), Haldoupis et al. (2007), and Ellyet and Goldsborough (1976). There are also numerous studies whose results are inconclusive. For example, Bagga- 


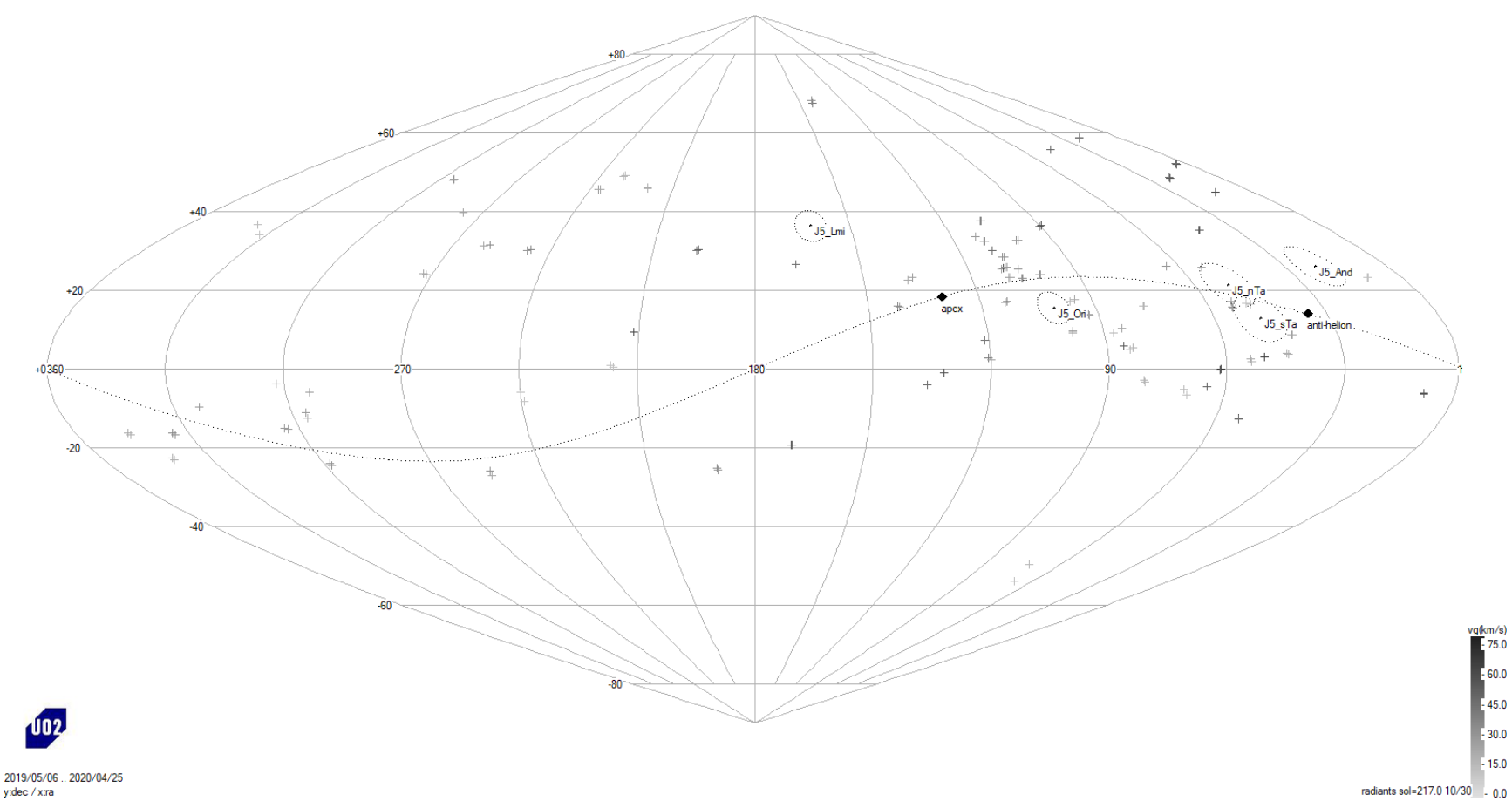

Figure 2. A radiant map of meteor observations by the Sharjah and Al-Yahar stations during the period May 2019-April 2020.
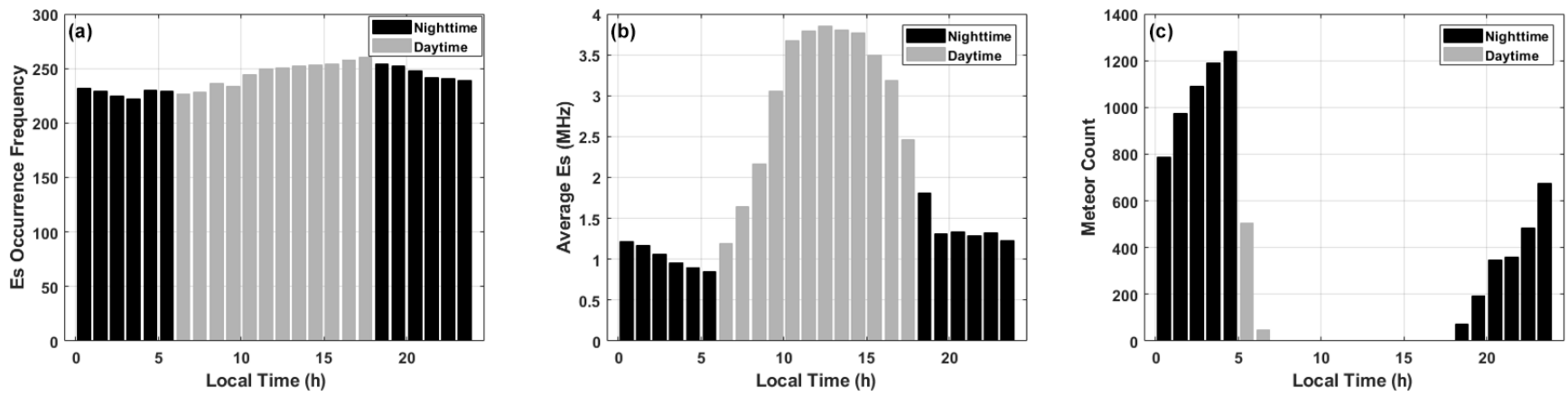

Figure 3. Simultaneous monitoring of meteors and the Es layer over the Arabian Peninsula from May 2019 to April 2020. (a) Es occurrence frequency as a function of local time. (b) Hourly average of foEs recorded using ionosonde. (b) Hourly meteor count.

ley and Steel (1984) were unable to find any correlation between meteor activity and the Es layers' occurrence. Kotadia and Jani (1967) reported that they did not find any increase in the occurrence of the Es layers during a period of anomalously large increase in meteor incidence in 1963 but instead found that the Es layers were formed less frequently during that period, suggesting an inverse relationship between the formation of the Es layers or meteor incidents. The results presented in this paper also follow a similar pattern, with foEs decreasing significantly during the period between October 2019 and January 2020, even with the increased meteor count during that period (see Fig. 4). This may be because plasma density abnormalities may exist which may cause ionograms to record scatter echoes beyond the foEs. Crossfield plasma instabilities cause the abnormalities due to the various electrodynamic processes in the ionosphere. These instabilities are triggered by the enhancement of plasma density in a particular volume when an external force acts on that same volume. A small disturbance can then lead to the separation of charges, which produces a small electric field, which with the presence of the geomagnetic field increases the disturbance (Simon, 1963). Meteoric activity may provide metallic ions to the ionosphere, but they may not be displayed in ionograms if the conditions are unfavorable. The aforementioned instabilities have been shown to be capable of producing the diffuse type of Es layer (Tsuda et al., 1969). The formation of this diffuse layer may cause the ionogram to display scatter echoes that exceed the actual critical frequency of the sporadic-E layer formed as a result of metallic ions deposited by meteors. This may be why a good corre- 

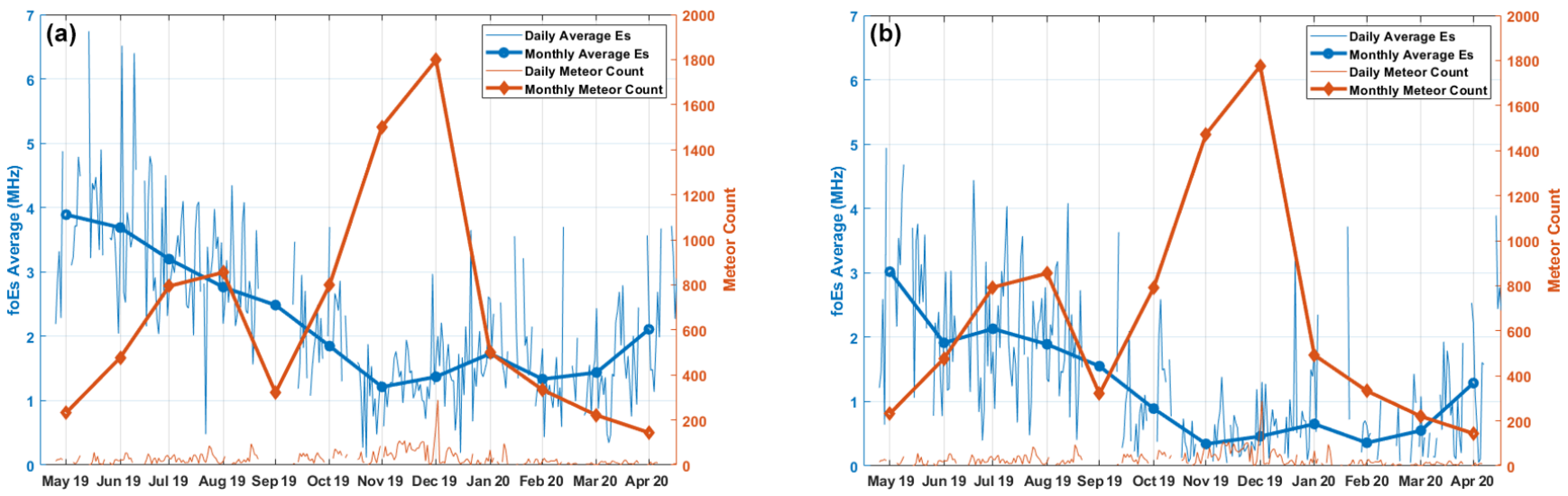

Figure 4. Daily and monthly averages of foEs and meteor count over Sharjah. (a) Including all observations (24 h). (b) Nighttime observations only.

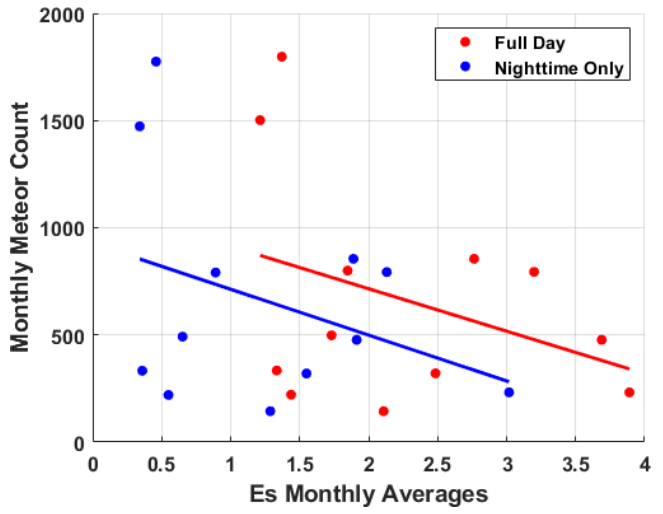

Figure 5. Relationship between foEs monthly averages and monthly meteor count observed at Sharjah.

lation between meteor activity and the Es layer is not seen (Chandra et al., 2001), which is also confirmed by the correlation plot in Fig. 5. It is shown in Fig. 5 that the annual variation of both observations, on average, does not correlate monthly, having linear correlation coefficients less than -0.35 (negative 0.35 ) for both full-day and nighttime observations.

Figure 4 shows differences between the variations in foEs and meteor counts observed at both small and large timescales. The Es layer may be affected by differences in climatology and wind dynamics. For example, long-period zonal and meridional winds at the mesopause region, with periods between 2 and $18 \mathrm{~d}$, may be considered to be planetary wave activity. Planetary waves have been observed to have strong variability between different seasons, with periods of $2 \mathrm{~d}$ in the summer, $5 \mathrm{~d}$ in spring, and even exceeding $10 \mathrm{~d}$ during the winter (Jacobi et al., 1998). Studies have proposed vortex flows associated with planetary waves to explain the seasonal dependence of sporadic-E layers (Shalimov et al., 1999). Vortex flows are already known to affect the development of E layers (Pancheva et al., 2003). The meteor count may also be influenced by some biases. A number of the recorded meteors may not be metallic in nature and would not deposit any metallic ions in the ionosphere, possibly explaining why a higher meteor count during winter months did not amount to a higher average foEs. Nevertheless, visual meteor counts may not include all meteors. The metallic ions deposited by a meteor in the ionosphere may not be proportional to the meteoric activity as well (Haldoupis et al., 2007). The exact relationship between metallic ion densities and meteoric activity is unknown, and the transportation of metallic ions by neutral winds is not accounted for. Due to these uncertainties, the incongruous relationship between foEs and visual meteors count is not unexpected; however, they are not enough to explain the incongruity. Another possible scenario arises when neutral winds are considered, which could transport metallic ions to the local ionosphere under study irrespective of the number of observed meteors (Haldoupis et al., 2007). This may be an explanation of the inverse correlation between foEs and meteor counts observed during summer months.

One can expect to see a meteor entering the Earth's atmosphere every $10 \mathrm{~min}$ or so, but there are predictable times during the year when the Earth's atmosphere is full of them, and these are referred to as meteor showers (Kronk, 2014). These showers occur monthly, with some meteor showers more pronounced than others, depending on their parents' progenitors (Collins, 2020). We can see about 30 meteor showers during the year. Since the meteors in each shower seem to come from a certain point in the sky, the shower is named after the constellation from which the meteors come. The Quadrantids, the Perseids, and the Geminids are the most prominent of all meteor showers. Table 2 shows the data obtained from the UAEMMN network about the meteor showers. The data are taken from the same 1-year study period used in this work. We can clearly observe that most meteor showers occurred from the period from August to December and 
Table 2. Meteor showers observed by the UAEMMN network.

\begin{tabular}{llrrlr}
\hline Constellation & Hourly dates & Rate & $\begin{array}{l}\text { Speed } \\
(\mathrm{km} / \mathrm{s})\end{array}$ & $\begin{array}{l}\text { Shower } \\
\text { name }\end{array}$ & $\begin{array}{r}\text { Quantity from the } \\
\text { UAEMMN towers }\end{array}$ \\
\hline Capricorn & 3 July-15 August & 5 & 41 & Capricornids & 6 \\
Perseus & 10-14 August & 40 & 60 & Perseids & 2 \\
Taurus & 1-7 November & 8 & 30 & Taurids & 10 \\
Gemini & 10-13 December & 50 & 35 & Geminids & 17 \\
Monocerous & 5-20 December & 15 & 35 & Monocerotids & 2 \\
Hydra & 3-15 December & 3 & 58 & Hydrids & 4 \\
\hline
\end{tabular}

resulted in a significant increase in the numbers of visual meteors observed in the UAE (see Fig. 4). However, it seems quite understandable here that not all those meteor showers contributed to the presence of the Es layer in the UAE since the Es layer observations were higher in summer than during the winter months.

The Es layer may not be observed if the meteoric activity period does not provide long-lived metallic ions in the background plasma density. However, under favorable conditions, the meteoric debris consisting mostly of metallic ions could be converged to form sharp layers of ionization leading to density gradients responsible for ionospheric irregularities and spreading of the echoes in the ionograms. Since the ionospheric background conditions considerably vary with latitudinal region, simultaneous observations from different geographical regions would be needed to confirm a certain meteoric activity and its linkage with the appearance of the Es layer. Therefore, a thorough analysis using the systematic analysis of past data taken simultaneously from different latitudinal regions yields a better picture of the role of meteoric activity in the E-region ionization.

\section{Conclusions}

In this paper, simultaneous observations of foEs and the meteoric influx (meteor count rates through visual cameras) show no diurnal or seasonal dependence over the Arabian Peninsula. We report the seasonal observations of the Es layer simultaneously taken with the visual count observations from a geographical region which has not been reported before. However, no attempt was made to link the simultaneous observation of the Es layer and meteor influx in detail.

Our 1-year observations clearly show that the Es layer intensity is not dependent on the presence of meteor flux since the meteor count trend, which peaks in winter and declines in summer, is found to be uncorrelated with the trend observed for Es layer intensity (see Figs. 4 and 5). This may have happened because plasma density abnormalities may exist which may cause ionograms to record scatter echoes beyond the foEs. The abnormalities are caused by plasma instabilities due to the various electrodynamic processes in the ionosphere. Meteoric activity may provide metallic ions to the ionosphere, but they may not be displayed in ionograms if the conditions are unfavorable. This may have been the reason why a good correlation between meteor activity and the Es layer intensity cannot be seen by our two collocated instruments. Such results have rarely been reported in the literature and do not comply with frequently reported studies which established a strong seasonal correlation between daily meteor counts with daily averages of the Es layer occurrences, as mentioned in the references above. It is also important to note that this study, unlike many of the previous studies, used visual observations for observing meteors. Since the data are manually checked and verified from the recorded visual data, unlike for radio-based radar observations where the rate of false observations is very high, the study is likely to provide a real picture since there is very little chance of having false data. Nevertheless, the authors believe that a more detailed study is required to fully investigate and properly identify the Es layer seasonal dependence on the meteor influx in the region around the Arabian Peninsula.

Data availability. All data used in this work are available from the dataverse of SWI Lab and acquired and managed by the Sharjah Academy for Astronomy, Space Sciences and Technology (https://dataverse.harvard.edu/dataset.xhtml?persistentId=doi: 10.7910/DVN/U2UNWE, last access: 2 November 2020, SWI Lab, 2020).

Author contributions. MMS, as principal investigator, performed conceptualization, investigation, data curation, and written the original draft. GG contributed with investigation, software coding, data curation and with review and editing of the manuscript. AA participated in software coding and with review and editing of the manuscript. ME Sharif helped perform data simulation and with review and editing of the manuscript. IF reviewed and edited the manuscript.

Competing interests. The authors declare that they have no conflict of interest. 
Acknowledgements. The authors are grateful to the two anonymous reviewers for their valuable comments which helped improve the quality of the paper.

Review statement. This paper was edited by Ana G. Elias and reviewed by two anonymous referees.

\section{References}

Baggaley, W. J. and Steel, D. I.: The seasonal structure of ionosonde Es parameters and meteoroid deposition rates, Planet. Space Sci., 32, 1533-1539, https://doi.org/10.1016/0032-0633(84)90021-7, 1984.

Brown, P., Stober, G., Schult, C., Krzeminski, Z., Cooke, W., and Chau, J. L.: Simultaneous optical and meteor head echo measurements using the Middle Atmosphere Alomar Radar System (MAARSY): Data collection and preliminary analysis, Planet. Space Sci., 141, 25-34, https://doi.org/10.1016/j.pss.2017.04.013, 2017.

Ceplecha, Z., Borovicka, J., Elford, W. G., ReVelle, D. O., Hawkes, R. L., Porubcan, V., and Šimek, M.: Meteor phenomena and bodies, Space Sci. Rev., 84, 327-471, https://doi.org/10.1023/A:1005069928850, 1998.

Chandra, H., Sharma, S., Devasia, C. V., Subbarao, K. S. V., Sridharan, R., Sastri, J. H., and Rao, J. V. S. V.: Sporadic-E associated with the Leonid meteor shower event of November 1998 over low and equatorial latitudes, Ann. Geophys., 19, 59-69, https://doi.org/10.5194/angeo-19-59-2001, 2001.

Collins, P. C.: Flashes in the Sky: The Origins of Meteors. ThoughtCo, Aug. 27, 2020, avaialable at: https://www. thoughtco.com/origins-of-meteors-4148114, last access: 13 October 2020.

Ellyet, C. D. and Goldsborough, P. F.: Relationship of meteors to sporadic-E 1, A sorting of facts, J. Geophys. Res., 81, 61316134, https://doi.org/10.1029/JA081i034p06131, 1976.

Feng, W., Marsh, D. R., Chipperfield, M. P., Janches, D., Höffner, J., Yi, F., and Plane, J. M. C.: A global atmospheric model of meteoric iron, J. Geophys. Res.-Atmos., 118, 9456-9474, https://doi.org/10.1002/jgrd.50708, 2013.

Fernini, I., Al-Naimiy, H., Talafha, M., Jami, I. A., Al-Owais, A., Fernini, R., Ahmad, A., Sharif, M., Al-Naser, M., Eisa, Y., Zarafshan, S., Subhi, S., Adwan, A., and Al-Ahbabi, M.: The UAE Meteor Monitoring Network, J. Instrument., 15, T06007, https://doi.org/10.1088/1748-0221/15/06/t06007, 2020.

Haldoupis, C., Pancheva, D., Singer, W., Meek, C., and MacDougall, J.: An explanation for the seasonal dependence of midlatitude sporadic E layers, J. Geophys. Res.-Space, 112, A06315, https://doi.org/10.1029/2007JA012322, 2007.

Jacobi, C., Achminder, R., and Kürschhner, D.: Planetary wave activity obtained from long-period (2-18 days) variations of mesopause region winds over central Europe $\left(52^{\circ} \mathrm{N}, 15^{\circ} \mathrm{E}\right)$, J. Atmos. Sol.-Terr. Phy., 60, 81-93, https://doi.org/10.1016/S1364-6826(97)00117-X, 2018.

Kopp, E.: On the abundance of metal ions in the lower ionosphere, J. Geophys. Res.-Space, 102, 9667-9674, https://doi.org/10.1029/97JA00384, 1997.
Kotadia, K. M., and Jani, K. G.: Sporadic-E ionization and anomalous increase in the rate of radar meteor counts during 1963, J. Atmos. Sol.-Terr. Phy., 29, 221-223. https://doi.org/10.1016/0021-9169(67)90137-7, 1967.

Kozlowski, S. K., Pawłaszek, R. K., Olech, A., Raj, A., Zoładek, P., Litwicki, M., Sybilski, P., Drzał, M., Hus, S., Słonina, M., Flohrer, T., and Funke, Q.: Omnisky: wide angle multi-camera station network concept for re-entry detection, Proc. 1st NEO and Debris Detection Conference, Darmstadt, Germany, 22-24 January 2019, published by the ESA Space Safety Programme Office, available at: http://neo-sst-conference.sdo.esoc.esa.int, last access: January 2019.

Kronk, G. W.: Meteor Showers: an Annotated Catalog, The Patrick Moore Practical Astronomy Series (2 Edn.), https://doi.org/10.1007/978-1-4614-7897-3, ISBN 9781461478966, Springer, 2014.

SWI Lab: Es and Meteor Counts near Arabian Peninsula, available at: https://dataverse.harvard.edu/dataset.xhtml?persistentId=doi: 10.7910/DVN/U2UNWE (last access: 2 November 2020), Harvard Dataverse, V1, 2020.

Lima, L. M., Araújo, L. R., Alves, E. O., Batista, P. P., and Clemesha, B. R.: Variations in meteor heights at $22.7^{\circ} \mathrm{S}$ during solar cycle 23, J. Atmos. Sol.-Terr. Phy., 133, 139-144, https://doi.org/10.1016/j.jastp.2015.08.015, 2015.

Pancheva, D., Haldoupis, C., Meek, C. E., Manson, A. H., and Mitchell, N. J.: Evidence of a role for modulated atmospheric tides in the dependence of sporadic E on planetary waves, J. Geophys. Res., 108, 1176, https://doi.org/10.1029/2002JA009788, 2003.

Plane, J. M. C., Feng, W., and Dawkins, E. C. M. D.: The mesosphere and metals: Chemistry and changes, Chem. Rev., 115, 4497-4541, https://doi.org/10.1021/cr500501m, 2015.

Shaikh, M. M., Fernini, I., Gopakumar, G., and Alameri, N. M.: Occurrence of pre-sunset L-band scintillation due to strong presence of sporadic-E over Arabian Peninsula, Adv. Space Res., 65, 2412-2423, https://doi.org/10.1016/j.asr.2020.02.011, 2020a.

Shaikh, M. M., Gopakumar, G., Hussein, A., Kashcheyev, A., and Fernini, I.: Daytime GNSS scintillation due to Es over Arabian Peninsula during low solar activity, Results in Physics, 20, 103761, https://doi.org/10.1016/j.rinp.2020.103761, 2020b.

Shalimov, S., Haldoupis, C., Voiculescu, M., and Schlegel, K.: Midlatitude $\mathrm{E}$ region plasma accumulation driven by planetary wave horizontal wind shears, J. Geophys. Res., 104, 28207-28213, 1999.

Simon, A.: Instability of a Partially Ionized Plasma in Crossed Electric and Magnetic Fields, Physics of Fluids, 6, 382, https://doi.org/10.1063/1.1706743, 1963.

Singer, W., von Zahn, U., and Weiß, J.: Diurnal and annual variations of meteor rates at the arctic circle, Atmos. Chem. Phys., 4, 1355-1363, https://doi.org/10.5194/acp-4-1355-2004, 2004.

SonotaCo.: UFOCaptureV2 Users Manual, Retrieved from available at: https://sonotaco.com/soft/UFO2/help/english/index.html (last access: 16 September 2020), 2005.

SonotaCo.: UFOAnalyzer V2 Users Manual, Retrieved from available at: https://sonotaco.com/soft/download/UA2Manual_ EN.pdf (last access: 16 September 2020), 2007a.

SonotaCo.: UFOOrbit V2 Users Manual, Retrieved from available at: https://sonotaco.com/soft/UO2/UO21Manual_EN.pdf (last access: 16 September 2020), 2007b. 
Stober, G., and Chau, J. L. A multistatic and multifrequency novel approach for specular meteor radars to improve wind measurements in the MLT region, Radio Sci., 50, 431-442, https://doi.org/10.1002/2014RS005591, 2015.

Tsuda, T., Sato, T., and Matsushita, S.: Ionospheric irregularities and the cross-field plasma instability, J. Geophys. Res., 74, 29232932, https://doi.org/10.1029/ja074i011p02923, 1969.

Vitek, S. and Nasyrova, M.: Real-Time Detection of Sporadic Meteors in the Intensified TV Imaging Systems, Sensors, 18, 77, https://doi.org/10.3390/s18010077, 2018.

Whitehead, J. D.: Recent work on midlatitude and equatorial sporadic E. J. Atmos. Terr. Phys., 51, 401, https://doi.org/10.1016/0021-9169(89)90122-0, 1989.
Yi, W., Xue, X., Chen, J., Dou, X., Chen, T., and Li, N.: Estimation of mesopause temperatures at low latitudes using the Kunming meteor radar, Radio Sci., 51, 130-141, https://doi.org/10.1002/2015RS005722, 2016.

Younger, P. T., Astin, I., Sandford, D. J., and Mitchell, N. J.: The sporadic radiant and distribution of meteors in the atmosphere as observed by VHF radar at Arctic, Antarctic and equatorial latitudes, Ann. Geophys., 27, 2831-2841, https://doi.org/10.5194/angeo-27-2831-2009, 2009.

Yu, B., Xue, X., Lu, G., Ma, M., Dou, X., Qie, X., Ning, B., Hu, L., $\mathrm{Wu}, \mathrm{J}$., and Chi, Y.: Evidence for lightning-associated enhancement of the ionospheric sporadic-E layer dependent on lightning stroke energy, J. Geophys. Res.-Space, 120, 9202-9212, https://doi.org/10.1002/2015JA021575, 2015. 